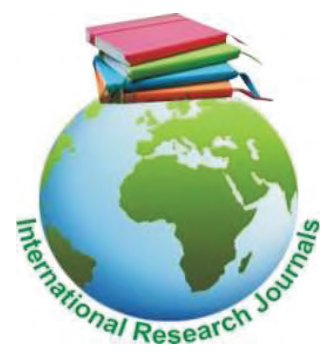

Probiotic Strains Used in Aquaculture Vol. 7(2) pp 043-055, October, 2018

DOI: http:/dx.doi.org/10.14303/irjm.2018.023

Available online http://www.interesjournals.org/IRJM

Copyright (C2018 International Research Journals

Full Length Research Paper

\title{
Probiotic Strains Used in Aquaculture
}

\author{
*Shoaibe Hossain Talukder Shefat \\ Department of Fisheries Management, Bangabandhu Sheikh Mujibur Rahman Agricultural University, Gazipur, \\ Bangladesh
}

*Corresponding e-mail: shoaibeshefat@gmail.com

\begin{abstract}
Aquaculture is the fastest growing animal food producing agricultural sector in the world which has been constrained by several factors. Infectious disease is a key limitations to the sustainable development of aquaculture sector. This paper reviewed the application and efficiency of probiotic microorganisms in aquaculture to prevent infectious diseases and their effects on fish immunology. Information was collected from different secondary sources like journals, reports, articles and electronic media and arranged chronologically. The study reveals that, currently, many probiotic products extracted from different species of bacteria including Bacillus sp., Lactobacillus sp., Carnobacterium sp., Enterococcus sp. and a yeast Saccharomyces cerevisiae are commercially available for use in aquaculture. Probiotics have gained popularity in aquaculture as an alternative to the antibiotic in the prevention of infectious diseases of fish because probiotics are eco-friendly. This review also shows that, probiotics have significant effect on growth rate, feed utilization capacity and the immune performance of finfish, shrimp, prawns and crabs in aquaculture. Probiotics are able to interfere with colonization of harmful pathogens and to improve the water quality through decomposition of uneaten food materials, nitrate and other organic materials.
\end{abstract}

Keywords: Aquaculture, food security, infectious disease, immunity, probiotics, microencapsulation.

Abbreviations: SGR: Specific Growth Rate; FCR: Food Conversion Ratio; PER: Protein Efficiency Ratio; WSSV: White Spot Syndrome Virus; IgM: Immunoglobulin M; APS: Astragalus Polysaccharide; NASS: National Agricultural Statistics Service; USDA: United States Department of Agriculture; FISH: Fluorescent in Situ Hybridization.

\section{INTRODUCTION}

Aquaculture is the fastest growing and most promising food producing agricultural sector which contributes almost half to the global fish production. It also provides employment opportunities and great contribution to the human food security and socioeconomic development in many countries (FAO, 2008). Sustainable development of aquaculture have to face many challenges like disease prevention, improving resistance to pathogens, increasing growth performance and immunomodulation. Infectious diseases are the key threats to aquaculture which can result in economic loos causing high mortality in farmed fishes (Assefa and Abunna, 2018). Almost 90\% production loss was caused by disease in rainbow trout (Oncorhynchus mykiss) culture in 2009 (NASS, 2010). A major tool in prevention of diseases in fish, shrimp and crab aquaculture was antibiotics until now; but treating infectious diseases with antibiotics have been proven unsustainable and ineffective as pathogens can develop resistance against antibiotics (Ayisi et al., 2017). This problem demands for alternatives of antibiotic for disease control in aquaculture. Application of probiotics in combination with prebiotics or alone have been reported to be a suitable alternative of antibiotics, because biological control is the best approaches against infectious disease (Maqsood et al., 2011).

Host species cannot utilize many important nutrients, but the gut microbiota can metabolize and convert them to end products like short-chain fatty acids. So, modulation of the intestinal microbiota of aquatic organisms in a positive way is very important which can 
be done administering probiotics (Wang et al., 2008; Merrifield et al., 2010; Dimitroglou et al., 2011; Gioacchini et al., 2014; Ringo et al., 2014). Probiotics are the beneficial microorganisms including bacteria and yeast which confers a health benefit to the host when administered in adequate amount (WHO, 2002). Probiotics are bioactive, non-digestible and fermentable food materials which provide benefits to the host animal through stimulation of its growth and activity of internal microorganisms (Ayisi, 2017). Probiotics are beneficial for the hosts, they are able to persist in the digestive tract because of their tolerance to acid and bile salts (Cruz et al., 2012). The use of probiotics has gained increasing scientific and commercial interest and are now quite commonplace in health - promoting foods to therapeutic, prophylactic and growth supplements (Nayak, 2010; Kiron, 2012; Ringo et al., 2014). It has been reported that, Probiotics have important beneficial effects on aquatic animals like increasing disease resistance and nutrient availability (Merrifield et al., 2010; Carnevali et al., 2014; Ringo et al., 2014). This review was conducted to investigate the application and efficiency of probiotic microorganisms and their products in aquaculture to control infectious diseases of fish and increasing immune response to the harmful pathogens. This paper also reviewed the probiotic products currently available in the market for use in aquaculture for the prevention and control of infectious fish diseases.

\section{REVIEW OF FINDINGS}

Probiotics are alive or dead whole microorganism or part of a microorganism or extract of microorganism which confers health benefits to the host when administered at appropriate dose and improve disease resistance, growth performance, feed conversion ratio (FCR) and stress resistance (Hoseinifar et al., 2014). The origin of using of probiotics in aquaculture is not clear from the historical perspective and available literatures but, evidence exists on usage of probiotics in extensive finfish and invertebrate culture in China and India. It has been reported that, the word probiotics was first used by Lilly and Stillwell in 1965 to denote health promoting bacteria which was then defined by Fuller as a live microbial feed supplement having ability to improve the microbial balance of host animal in 1989 (Balcazar et al., 2006; Austin et al., 2012).

\section{Sources of probiotics}

Westerdahl et al. (1991) preferred the host-derived micro-organisms as probiotics to be used against pathogen. Probiotic microorganisms may be derived from intestine or guts of healthy fish, water of rearing environment, sediments of culture tank, other animals, and different fermented food products. The efficacy of commercial probiotic is not clear from the literature stock but host-derived probiotics were found beneficial to host microbiota isolated from the gastrointestinal tract of aquatic (Hai, 2015). Those microorganisms are beneficial which lives inside a healthy hosts and they are argued to be the essential part of natural defense system (Gomez et al., 2013). Terrestrial microorganisms were also proven ineffective as probiotic for marine organisms (Vazquez et al., 2003). Lactococcus lactis, Lactobacillus brevis, Lactobacillus collinoides, Lactobacillus coryniformis, Enterococcus faecalis, Citrobacter freundi, Lactobacillus farciminis, Lysinibacillus fusiformis, Pseudomonas fluorescens, Bacillus circulans, Enterococcus durans, Streptococcus sp. I, Streptococcus sp. II, Leuconostoc sp., Enterococcus faecium and many other potential probiotics have been isolated from Oreochromis niloticus (Reda et al., 2017). Bacillus licheniformis, Enterococcus faecalis, Bacillus pumilus, Enterococcus faecium, Lactobacillus lactis, Bacillus subtilis were isolated from Rainbow trout and Mugil cephalus having high potential to be used as aquaculture probiotics (Hai, 2015).

\section{Administration strategies}

Immunomodulatory activity of probiotics depends on various factors like source of probiotic, dose of probiotic, method of administration and the duration of supplementation (Hai, 2015). Proper administration method is a key factor to use the probiotics in aquaculture.

- Dietary Administration: Direct incorporation of probiotic in pelleted feed is one of the most important and widely applicable administration of probiotics. Probiotics are directly applied in the form of spore with feed pellets (Assefa and Abunna, 2018). During the addition of probiotics, the viability should be checked continuously to confirm protective enhanced immunity in the fish. They can be added as freeze-dried cultures that can be mixed with lipids as top dressings in the feed (De et al., 2014).

- Microencapsulation: The widely used administration strategy is encapsulation. Encapsulation helps by improving nutritional values and proper delivery of the microbe to the host (Assefa and Abunna, 2018). In this process, probiotic strains at high density are encapsulated in a colloidal matrix using alginate, chitosan, carboxymethylcellulose, or pectin to physically and chemically protect the microorganisms (Hermosillo et al., 2012). In aquaculture, application of Shewanella putrefaciens was done by encapsulating in calcium alginate which demonstrated the survival of encapsulated probiotic cells through the gastrointestinal tract of sole, Solea senegalensis. Encapsulation in alginate 
matrices protects bacteria from low $\mathrm{pH}$ and digestive enzymes (Kumar et al., 2016).

- Immobilized Probiotics: Immobilization of Probiotic is a new technique, extensively used in dairy and pharmaceutical industries which has been reported to be advantageous (Assefa and Abunna, 2018). It is a new technology, extensively used in the dairy and pharmaceutical industries, applied to Lactobacillus species. In addition, cell immobilization offers many advantages for biomass and metabolite production compared with free cell systems (De et al., 2014).

\section{Application of probiotics}

Probiotics can be applied in different form such as using only Probiotic strains, Probiotics with plant products and Probiotics with yeast extracts. Using probiotics with plant product is a promising disease control approach which can improve growth performance, haematological parameters, immune response and disease resistance of fish (Ringo and Song, 2015). But, little information is available on the effect of plant-probiotic mixture in aquaculture (Ringo and Song, 2015).

Using Only Probiotics: Carnobacterium sp. successfully reduced the diseases of salmonids caused by Vibrio ordalii, Aeromonas salmonicida and Yersinia ruckeri (Robertson et al., 2000); Vibrio anguillarum improved disease resistance of cod fry; multi-strain probiotics provide synergistic beneficial effects on the host health. A mixture of Bacillus subtilis and Lactobacillus acidophilus provided higher protection against harmful pathogens in tilapia such as Aeromonas hydrophila, Pseudomonas fluorescens and others (Sharifuzzaman and Austin, 2017).

Probiotics with Plant Extracts: Supplementation of Lactobacillus sakei and Scutellaria baicalensis plant extract (Harikrishnan et al., 2011), Lactobacillus plantarum with polysaccharide and Lactobacillus plantarum with Helianthus tuberosus agar (Van Doan et al., 2014; Ringo and Song, 2015), Bacillus sp. and a mixture herb extracts (Yu et al., 2009), mixture of Pediococcus parvulus, Candida parapsilosis (yeast) and Echinacea purpurea and Uncaria tomentosa (Peraza-Gomez et al., 2014) and many others have been reported to increase growth rate, FCR, PER, SGR and disease resistance in fish and shellfish.

Probiotics with Yeast: Probiotic bacteria Bacillus licheniformis with yeast extract significantly (Hassaan et al., 2014), Shewanella putrefaciens with $\beta$-glucans (Guzman-Villanueva et al., 2014); Vibrio alginolyticus with $\beta$-glucans (Fan et al., 2010; Ringo and Song, 2015) and their combinations increased immune response, SGR, FCR, PER, survival rate, serum IgM level, anti-protease activity and phagocytic activity in Nile tilapia, shrimp and gilthead seabream. Injecting Bacillus subtilis with APS and Tuckahoe improved SGR, immune response and disease resistance against Vibrio splendidus (Sharifuzzaman and Austin, 2017).

\section{Mechanism of actions}

The mechanisms of action of probiotics were not completely understood. Probiotics can expel out harmful pathogens after entering the digestive tract of host, the beneficial micro - organism produce inhibitory molecules, compete with pathogens for binding site, nutrient, or energy and interfere with pathogen activities (Balcazar et al., 2006; Irianto and Austin, 2002). Some are capable to prevent pathogen growth on the gut surface. Addition of Lactobacillus lactis, L. plantarum and $\mathrm{L}$. fermentum reduced Aeromonas salmonicida, A. hydrophila, Vibrio anguillarum and Yersinia ruckeri in the intestinal mucus of rainbow trout (Balcazar et al., 2006). Mixture of Bacillus subtilis and Bacillus licheniformis significantly improved of FCR, SGR and PER in rainbow trout (Merrifield et al., 2010). The mechanisms of action of bacteria used as probiotics, although not yet fully elucidated, are described as following (Balcбzar et al., 2006; Ng et al., 2008; Walker 2008; Sherman et al., 2009):

- Competition for binding sites: It is also known as "competitive exclusion", where probiotic bacteria bind with the binding sites in the intestinal mucosa, forming a physical barrier, preventing the connection by pathogenic bacteria.

- Production of antibacterial substances: Probiotic bacteria synthesize compounds like hydrogen peroxide and bacteriocins, which have antibacterial action on the pathogenic bacteria. They also produce organic acids that lower the environment's $\mathrm{pH}$ of the gastrointestinal tract, preventing the growth of various pathogens and development of certain species of Lactobacillus.

- Competition for nutrients: Probiotics completes with the harmful pathogens for nutrition absorption which reduces the amount for nutrients. These lack of nutrients available that may be used by pathogenic bacteria is a limiting factor for their maintenance.

- Stimulation of immune system: Some probiotics bacteria are directly linked to the stimulation of the immune response, by increasing the production of antibodies, activation of macrophages, T-cell proliferation and production of interferon. 


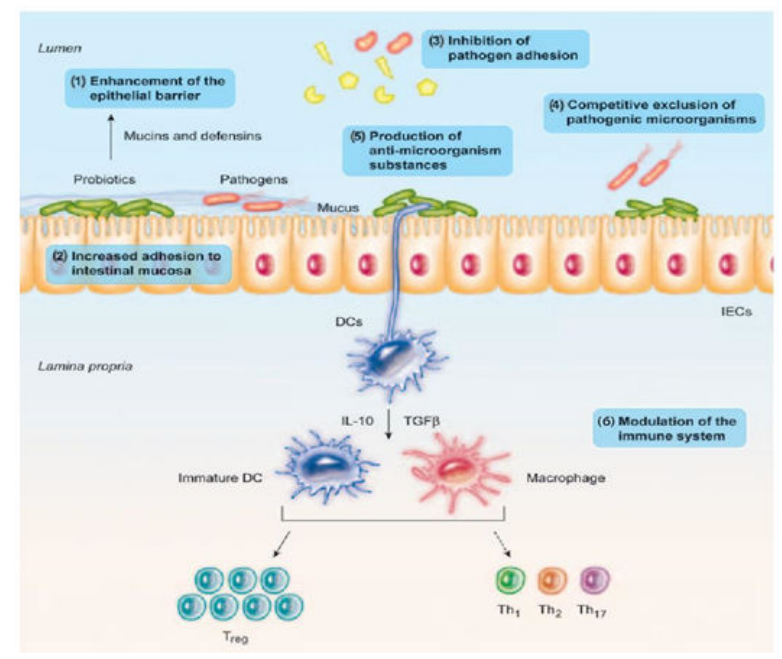

Figure 1. Mechanisms of action of Probiotics in Fish and other organisms (Bermudez-Brito et al., 2012)

\section{Effects of probiotics}

Probiotics are used in aquaculture to increase the growth performance of cultured species, to increase the appetite and digestibility of fish. Probiotics have the capacity to control diseases, promote growth rate, acts as source of nutrients, contribute in feed digestion, and improve the immune response. Probiotic are promising approach to inhibit the virulence of pathogens and to control the diseases in aquaculture species. Probiotics are capable to release chemical substances having bactericidal or bacteriostatic effect (De et al., 2014). Probiotics have important beneficial effects on the digestive system of fish. Probiotic can synthesize enzymes like amylase, proteases and lipases. Nutrients absorption capacity increases when probiotics are added to the feed in appropriate dose (Merrifield et al., 2010). High level of probiotics in fish ponds can minimize the accumulation of dissolved and particulate matters in the growing season and balance the production of phytoplankton (Ibrahem, 2015). It has been reported that, Probiotics increased stress tolerance in intensive aquaculture zebra fish (Danio rerio) (Cruz et al., 2012). Many of the aquatic microbes have been proven to enhance disease resistance in fish and shellfish species against multiple pathogens (Newaj-Fyzul et al., 2015). Prolonged administrations of probiotics induced immune responses of hosts, improved health status, improved disease resistance and increased growth rate. Swain et al. (2009) fed the Penaeus monodon with four probiotics and concluded that the probiotic strains effectively inhibited the pathogens, increased survival rate to Vibrio harveyiand disease resistance against Vibrio parahaemolyticus. He proved that the Streptococcus phocae and Enterococcus faecium isolated from brackish water shrimp is highly potential to control pathogenic vibriosis in shrimp culture (Swain et al., 2009). A LAB strain Lactobacillus plantarum MR03.12 showed the highest efficiency in reducing Vibrio harveyi pathogen. Supplemented diet containing Lactobacillus plantarum showed (L.) significantly increased relative growth rate (RGR), feed conversion ratio (FCR) and survival rate of Litopenaeus vannamei (Kongnum and Hongpattarakere, 2012). Nimrat et al., (2012) examined the effectiveness of mixed Bacillus probiotics and mode of action on growth, bacterial numbers and water quality in Litopenaeus vannamei and found that the Post larvae treated with probiotic exhibited higher growth, high survival of shrimp, increased beneficial bacteria and enhanced water quality (Nimrat et al., 2012).

\section{Available commercial probiotics}

A lot of probiotic microorganisms have been isolated and evaluated for use in aquaculture in prevention and control of infectious diseases of aquaculture species. Some of these have been isolated from aquatic species including finfish and shrimps, their intestines and guts, culture environment, terrestrial animals and other sources.

Table 1. Commercially available Probiotic products for use in aquaculture (Balcazar et al., 2006; Merrifield et al., 2010; Nayak, 2010; Cruz et al., 2012; Ringw et al., 2014; Hai, 2015; Ibrahem, 2015).

\begin{tabular}{|c|c|c|}
\hline SL. No. & Microorganisms & Target Species \\
\hline 1 & Bacillus sp. & Catfish, Penaeids \\
\hline 2 & Carnobacterium divergens & Gadus morhua \\
\hline 3 & Alteromonas sp. & Crassostrea gigas \\
\hline 4 & Lactobacillus helveticus & Scophthalmus maximus \\
\hline 5 & Lactobacillus lactis & Brachionus plicatilis \\
\hline 6 & Streptococcus thermophilus & Scophthalmus maximus \\
\hline 7 & Streptomyces & Xiphophorus helleri \\
\hline 8 & Lactobacillus casei & Poeciliopsis gracilis \\
\hline 9 & Bacillus sp. Vibrio $s p$. & Macrobrachium rosenbergii \\
\hline 10 & Bacillus coagulans & Cyprinus carpio, koi \\
\hline 11 & Enterococcus faecium & Anguilla anguilla \\
\hline 12 & Lactobacillus rhamnosus & Oncorhynchus mykiss \\
\hline 13 & Pseudomonas fluorescens & Oncorhynchus mykiss \\
\hline 14 & Pseudomonas sp. & Oncorhynchus mykiss \\
\hline 15 & Roseobacter sp. & Scallop larvae \\
\hline 16 & Saccharomyces cerevisiae & Litopenaeus vannamei \\
\hline 17 & Phaffia rhodozyma & Litopenaeus vannamei \\
\hline 18 & Vibrio alginolyticus & Salmonids \\
\hline
\end{tabular}




\begin{tabular}{|c|c|c|}
\hline 19 & Vibrio fluvialis & Oncorhynchus mykiss \\
\hline 20 & Tetraselmis suecica & Salmo salar \\
\hline 21 & Carnobacterium sp. & Hepialus gonggaensis \\
\hline 22 & Lactobacillus acidophilus & Clarias gariepinus \\
\hline 23 & Bacillus spp. & Farfantepenaeus brasiliensis \\
\hline 24 & Enterococcus sp. & Farfantepenaeus brasiliensis \\
\hline 25 & Lactococcus lactis & Epinephelus coioides \\
\hline 26 & Lactococcus helveticus & Scophthalmus maximus \\
\hline 27 & Bacillus sp. and Vibrio sp. & Macrobrachium rosenbergii \\
\hline 28 & Carnobacterium sp. & Hepialus gonggaensis \\
\hline 29 & Lactobacillus acidophilus & Clarias gariepinus \\
\hline 30 & Shewanella putrefaciens & Solea senegalensis \\
\hline 31 & Bacillus sp. & Penaeus monodon \\
\hline 32 & Lactobacillus acidophilus & Clarias gariepinus \\
\hline 33 & Bacillus coagulans & Pennaeus vannamei \\
\hline 34 & Lactobacillus delbrueckii & Dicentrarchus labrax \\
\hline 35 & Saccharomyces sp. & Penaeus monodon \\
\hline 36 & Bacillus subtilis & Paralichthys olivaceus \\
\hline 37 & Pediococcus acidilactici & Litopenaeus stylirostris \\
\hline 38 & Bacillus subtilis & Poecilia reticulata \\
\hline 39 & Lactobacillus rhamnosus & Danio rerio \\
\hline 40 & Lactobacillus acidophilus & Xiphophorus helleri \\
\hline 41 & Lactobacillus casei & Xiphophorus helleri \\
\hline
\end{tabular}

\section{Limitations and prospects}

Probiotic products activate the defense mechanism and innate immunity of host, influence the virulence of disease causing pathogen and stimulate the response to stressors, but these aspects have been investigated very less for sturgeons (Askarian et al., 2011; Ringo and Song, 2015). The possible mechanism of action of probiotics largely depend on probiotic-host interactions (Sharifuzzaman and Austin, 2017). But, there is uncertainties about the longevity of protection conferred by probiotics (Newaj-Fyzul and Austin, 2015). To date, aquaculture studies on probiotics in combination with plant products and $\mathrm{b}$ - glucan, have not investigated properly, the effect on epithelial barrier function, gut integrity and architecture, disease resistance against pathogenic bacteria (Sissener et al., 2009). Successful formulation of probiotics in combination with plant products and b-glucan is a complex issue and a little information is available from aquaculture studies (Gatlin et al., 2007). The impacts of probiotic strain or probiotic products on tilapia (Oreochromis niloticus) aquaculture has not been fully understood. Besides, commercially-available probiotic microorganisms do not provide beneficial effects on Nile tilapia (Hai, 2015). The combined use of probiotics and plant products is in its infancy, so the topic deserves further attention. An aspect that deserves attention is the dietary supplement, combination of probiotic bacteria and plant-based replacers in aqua feeds, as the continued growth and intensification of aquaculture has increased inclusion of plant based replacers in diets (Hansen et al., 2015). Further investigations on these issues alongside an environmental impact assessment of probiotics are key requirements to realize desirable outcomes in aquaculture. Clearly, there is a role for probiotics in fish and shellfish disease control strategies, and their use can not only help to replace some of the inhibitory chemicals currently used in aquaculture but also promote food and health safety (Sharifuzzaman and Austin, 2017).

\section{CONCLUSION}

The probiotics in aquatic environment is still a controversial concept due to lack of authentic evidence or real environment demonstrations on the successful use of probiotics and their mechanisms of action. Probiotic is an alternative to antibiotics and chemicals in aquaculture which provide better health benefits, higher growth rate, increased survival rates and produce safe organic fish products to meet the protein requirements of future generations. Further research on probiotics should focus on molecular biotechnology tools to gain a greater understanding of the modes of action because the exact mode of action of probiotics is not totally known in fish. Using immunohistochemistry, gene expression and proteomics can be used to explore the mechanisms of actions of probiotics. Researches on the interaction between probiotics and carbohydrate-to-lipid ratio can reduce pressures on feed nutrition in the intensive aquaculture industry. The FISH technique is a potential tool to characterize the dynamics of potential probiotic bacteria and their efficiency in the control of pathogenic bacteria in pathogen detection.

\section{ACKNOWLEDGEMENT}

The author is thankful to the Almighty Allah for enabling him to write this article, thankful to the Editor of International Research Journal of Microbiology for his continuous support, and patience, and also thankful to the respected reviewers for their invaluable comments and suggestions for the betterment and publication of this article. 


\section{Conflicts of Interest}

The author of this article declares that there is conflicts of interest or financial interests regarding the publication of this article.

\section{REFERENCES}

Ayisi CL, Apraku A, Afriyie G (2017). A Review of Probiotics, Prebiotics, and Synbiotics in Crab: Present Research, Problems, and Future Perspective. Journal of Shellfish Research. 36:799-806.

Assefa A, Abunna F (2018). Maintenance of Fish Health in Aquaculture: Review of Epidemiological Approaches for Prevention and Control of Infectious Disease of Fish. Veterinary medicine international.

Askarian F, Kousha A, Salma W, Ringø E (2011). The effect of lactic acid bacteria administration on growth, digestive enzyme activity and gut microbiota in Persian sturgeon (Acipenser persicus) and beluga (Huso huso) fry. Aquaculture Nutrition. 17:488-497.

Austin B, Austin DA, Austin B, Austin DA (2012). Bacterial fish pathogens. Heidelberg, Germany:Springer.

Austin B, Newaj-Fyzul A (2017). Diagnosis and Control of Diseases of Fish and Shellfish. John Wiley \& Sons.

Balcázar JL, De Blas I, Ruiz-Zarzuela I, Cunningham D, Vendrell D, Muzquiz JL (2006). The role of probiotics in aquaculture. Veterinary microbiology. 114:173-186.

Bermudez-Brito M, Plaza-Díaz J, Muñoz-Quezada S, Gómez-Llorente C, Gil A (2012). Probiotic mechanisms of action. Annals of Nutrition and Metabolism. 61:160-174.

Carbone D, Faggio C (2016 ). Importance of prebiotics in aquaculture as immunostimulants. Effects on immune system of Sparus aurata and Dicentrarchus labrax. Fish \& Shellfish Immunology. 54:172-1788.

Carnevali O, Zamponi MC, Sulpizio R, Rollo A, Nardi M, Orpianesi C, Silvi S, Caggiano M, Polzonetti AM, Cresci A (2004). Administration of probiotic strain to improve sea bream wellness during development. Aquaculture International. 12:377-386.

De BC, Meena DK, Behera BK, Das P, Mohapatra PD, Sharma AP (2014). Probiotics in fish and shellfish culture: immunomodulatory and ecophysiological responses. Fish physiology and biochemistry. 40:921-971.

Dimitroglou A, Merrifield DL, Carnevali O, Picchietti S, Avella M, Daniels C, Güroy D, Davies SJ (2011). Microbial manipulations to improve fish health and production-a Mediterranean perspective. Fish \& shellfish immunology. 30:1-6.

Defoirdt T, Sorgeloos P, Bossier P. Alternatives to antibiotics for the control of bacterial disease in aquaculture. Current opinion in microbiology. 2011 Jun 1;14(3):251-258.

Farzanfar A (2006). The use of probiotics in shrimp aquaculture. FEMS Immunology \& Medical Microbiology. 48:149-158. FAO.

Fisheries Topics: Governance: Fish health management in aquaculture. Text by Rohana Subasinghe (2008). In: FAO Fisheries and Aquaculture Department, Rome.

Gomez D, Sunyer JO, Salinas I (2013). The mucosal immune system of fish: the evolution of tolerating commensals while fighting pathogens.

Fish \& shellfish immunology. 35:1729-1739.

Gioacchini G, Giorgini E, Olivotto I, Maradonna F, Merrifield DL, Carnevali O (2014). The influence of probiotics on zebrafish Danio rerio innate immunity and hepatic stress. Zebrafish. 11:98-106.

Guzmán-Villanueva LT, Tovar-Ramírez D, Gisbert E, Cordero H, Guardiola FA, Cuesta A, Meseguer J, Ascencio-Valle F, Esteban MA (2014). Dietary administration of $\beta-1,3 / 1$, 6-glucan and probiotic strain Shewanella putrefaciens, single or combined, on gilthead seabream growth, immune responses and gene expression. Fish \& shellfish immunology. 39:34-41.

Gatlin III DM, Barrows FT, Brown P, Dabrowski K, Gaylord TG, Hardy RW, Herman E, Hu G, Krogdahl $\AA$, Nelson R, Overturf K. Expanding the utilization of sustainable plant products in aquafeeds: a review. Aquaculture research. 2007 Apr;38(6):551-579.

Harikrishnan R, Balasundaram C, Heo MS (2011). Fish health aspects in grouper aquaculture. Aquaculture. 32:1-21.

Hoseinifar SH, Ringø E, Shenavar Masouleh A, Esteban MÁ (2016). Probiotic, prebiotic and synbiotic supplements in sturgeon aquaculture: a review. Reviews in Aquaculture. 8:89-102.

Hai NV (2015). The use of probiotics in aquaculture. Journal of applied microbiology. 119:917-35.

Hermosillo OA, Mart PM, Ib AL, \& Ram HC (2012). Use of Probiotics in Aquaculture. International Scholarly Research Notices. 12:13.

Hassaan MS, Soltan MA, Ghonemy MM (2014). Effect of synbiotics between Bacillus licheniformis and yeast extract on growth, hematological and biochemical indices of the Nile tilapia (Oreochromis niloticus). The Egyptian Journal of Aquatic Research. 40:199-208.

Hansen AC, Waagbø R, Hemre GI. New B vitamin recommendations in fish when fed plant based diets. Aquaculture n (2015)utrition. 21:507-527.

Irianto A, Austin B (2002). Use of probiotics to control furunculosis in rainbow trout, Oncorhynchus mykiss (Walbaum). Journal of fish diseases. 25:333-342 
Ibrahem MD (2015). Evolution of probiotics in aquatic world: potential effects, the current status in Egypt and recent prospectives. Journal of advanced research. 6:765-791.

Kumar V, Roy S, Meena DK, Sarkar UK (2016). Application of probiotics in shrimp aquaculture: importance, mechanisms of action, and methods of administration. Reviews in Fisheries Science \& Aquaculture. 24:342-368.

Kiron V (2012). Fish immune system and its nutritional modulation for preventive health care. Animal Feed Science and Technology. 173:111-133.

Kongnum K, Hongpattarakere T (2012). Effect of Lactobacillus plantarum isolated from digestive tract of wild shrimp on growth and survival of white shrimp (Litopenaeus vannamei) challenged with Vibrio harveyi. Fish \& shellfish immunology. 32:170-177.

Maqsood S, Singh P, Samoon MH, Munir K (2011). Emerging role of immunostimulants in combating the disease outbreak in aquaculture. International Aquatic Research (Islamic Azad University, Tonekabon Branch). Vol. 3.

Merrifield DL, Dimitroglou A, Foey A, Davies SJ, Baker RT, Bøgwald J, Castex M, Ringø E (2010). The current status and future focus of probiotic and prebiotic applications for salmonids. Aquaculture. 302:1-8.

Martínez Cruz P, Ibáñez AL, Monroy Hermosillo OA, Ramírez Saad HC (2012). Use of probiotics in aquaculture. ISRN microbiology. 2012:916845.

Meidong R, Doolgindachbaporn S, Sakai K, Tongpim $\mathrm{S}$ (2017). Isolation and selection of lactic acid bacteria from Thai indigenous fermented foods for use as probiotics in tilapia fish Oreochromis niloticus. Aquaculture, Aquarium, Conservation \& Legislation. 10:455-463.

Nayak SK (2010). Probiotics and immunity: a fish perspective. Fish \& shellfish immunology. 29:2-14.

NewajFyzul A, Austin B (2015). Probiotics, immunostimulants, plant products and oral vaccines, and their role as feed supplements in the control of bacterial fish diseases. Journal of fish diseases. 38:937-955.

Ng SC, Hart AL, Kamm MA, Stagg AJ, Knight SC (2008). Mechanisms of action of probiotics: recent advances. Inflammatory bowel diseases. 15:300-310.

Nimrat S, Suksawat S, Boonthai T, Vuthiphandchai V (2012). Potential Bacillus probiotics enhance bacterial numbers, water quality and growth during early development of white shrimp (Litopenaeus vannamei). Veterinary microbiology. 159:443-450.

Peraza-Gómez V, Luna-González A, González-Prieto JM, Fierro-Coronado A, González-Ocampo HA (2014). Protective effect of microbial immunostimulants and antiviral plants against WSSV in Litopenaeus vannamei cultured under laboratory conditions. Aquaculture. 420:160-164.

Robertson PA, O'Dowd C, Burrells C, Williams P, Austin B (2000). Use of Carnobacterium sp. as a probiotic for Atlantic salmon (Salmo salar L.) and rainbow trout (Oncorhynchus mykiss, Walbaum). Aquaculture. 185(3-4):235-243.

Reda RM, Selim KM, El-Sayed HM, El-Hady MA (2017). In Vitro Selection and Identification of Potential Probiotics Isolated from the Gastrointestinal Tract of Nile Tilapia, Oreochromis niloticus. Probiotics and antimicrobial proteins. 17:1-2.

Ringø E, Olsen RE, Jensen I, Romero J, Lauzon HL (2014). Application of vaccines and dietary supplements in aquaculture: possibilities and challenges. Reviews in Fish Biology and Fisheries. 24(4):1005-1032.

Ringø E, Song SK (2016). Application of dietary supplements (synbiotics and probiotics in combination with plant products and $\beta$ glucans) in aquaculture. Aquaculture Nutrition. 22(1):4-24.

Sahu MK, Swarnakumar NS, Sivakumar K, Thangaradjou T, Kannan L (2008). Probiotics in aquaculture: importance and future perspectives. Indian journal of microbiology. 48:299-308.

Sissener NH, Sanden M, Bakke AM, Krogdahl A, Hemre GI (2009). A long term trial with Atlantic salmon (Salmo salar L.) fed genetically modified soy; focusing general health and performance before, during and after the parr-smolt transformation. Aquaculture. 294:108-117.

Swain SM, Singh C, Arul V (2009). Inhibitory activity of probiotics Streptococcus phocae PI80 and Enterococcus faecium MC13 against vibriosis in shrimp Penaeus monodon. World Journal of Microbiology and Biotechnology. 25:697-703.

Sherman PM, Ossa JC, JohnsonHenry K (2009). Unraveling mechanisms of action of probiotics. Nutrition in Clinical Practice. 24:10-14.

Vázquez JA, Cabo ML, González M, Murado MA (2003). Survival of lactic acid bacteria in seawater: a factorial study. Current microbiology. 47:508-513.

Van Doan H, Doolgindachbaporn S, Suksri A (2014). Effects of low molecular weight agar and Lactobacillus plantarum on growth performance, immunity, and disease resistance of basa fish (Pangasius bocourti, Sauvage 1880). Fish \& shellfish immunology. 41:340-345.

Wang YB, Li JR, Lin J (2008). Probiotics in aquaculture: challenges and outlook. Aquaculture. 281:1-4.

World Health Organization (2002). The world health report 2002: reducing risks, promoting healthy life. World Health Organization 
8 Int. Res. J. Microbiol.

Walker WA. Mechanisms of action of probiotics (2008). Clinical Infectious Diseases. 46(Supplement_2):S87-91.

Yu MC, Li ZJ, Lin HZ, Wen GL, Ma S (2008). Effects of dietary Bacillus and medicinal herbs on the growth, digestive enzyme activity, and serum biochemical parameters of the shrimp Litopenaeus vannamei. Aquaculture international. 16:471-480. 